\title{
Fair Deal: spelling it out for service users ${ }^{\dagger}$
}

\author{
Maurice Arbuthnott ${ }^{1}$
}

The Psychiatrist (2010), 34, 290-291, doi: 10.1192/pb.bp.109.028183

${ }^{1}$ Faculty of Rehabilitation and Social Psychiatry, Royal College of Psychiatrists

Correspondence to Maurice Arbuthnott (mauricea@easy.com)
Summary The Royal College of Psychiatrists' Fair Deal campaign provides a welcome guide to the values and priorities for mental health practitioners and services in promoting service users' recovery. It was developed in consultation with service users and carers. This paper presents an alternative interpretation of the Fair Deal, a parallel manifesto of aspirations and ideals that can enhance the spirit of concord and partnership between service users and mental health professionals.

Declaration of interest M.A. is a service user representative for the Executive Committee of the Faculty of Rehabilitation and Social Psychiatry, Royal College of Psychiatrists. This paper does not represent an official view from the Faculty.

\section{The Fair Deal alphabet}

\section{$F$ for freedom}

Freedom must be a treatment goal as soon as a service user makes contact with mental health services, however long the process may take. It should be considered in terms of 'freedom from' (negative experiences) and 'freedom to': freedom to make choices about treatment; freedom to contribute socially; freedom to social expression; freedom to make independent decisions; freedom from psychosis; freedom from coercive treatment; freedom from stigma and discrimination; freedom from unrealistic expectations and goals. It must be a treatment goal to restore the 'freedom to' as soon as possible, yet the process of hospital discharge can be almost as traumatic as admission. Once liberated from the confines of psychosis and treatment, the service user is suddenly faced with comparative freedom and has to relearn how to handle this. This process needs to be much better supported by mental health services.

\section{A for autonomy}

Service users aspire to treatment that allows them to lead a full and independent life in the community, with a minimum of support. The process of recovery and regaining autonomy, however, is often long and complex and requires much professional help, support and encouragement as well as personal resilience and a willingness to challenge oneself. Treatment must hold onto the aim of achieving independent living rather than cultivating dependency. The degree of autonomy to which an individual aspires will vary, but a healthy move towards the least intrusive psychiatric care wherever possible and practicable should be ingrained in every mental health practitioner's work. Autonomy means 'self-rule' enhanced by the therapeutic process of gaining or

"See editorial, pp. 265-267, this issue regaining skills and confidence that service users may achieve through rehabilitation.

\section{I for inclusion}

Social inclusion is self-defined and it is up to each individual to find a level of inclusion - or indeed exclusion - that they are happy with. Service users should have the freedom and social means to do this. We consider the social inclusion of service users against a historical background where those with mental health problems were totally excluded from society and incarcerated within asylums. This is still only recent history. Social inclusion of the mentally ill is, from a general public perspective, a 'new' concept. However, the power that the Mental Health Act grants services in enforcing treatment on individuals means that exclusion is still a part of many service users' experience of treatment, not just those who are a danger either to themselves or to others and where exclusion may become a necessity. It is therefore part of the recovery process for mental health practitioners and services to assist the individual in developing their skills, abilities, confidence and motivation to be included in society. However, some service users and carers perceive social inclusion negatively as indiscriminate government policy to force vulnerable individuals off benefit support and into the job market, to close much needed day services and turn users out into the wider community whether or not they have the coping skills.

\section{$\mathrm{R}$ for recovery and rehabilitation}

The Royal College of Psychiatrists' campaign goals of 'recovery and rehabilitation' resonate well, although rehabilitation usually comes first as it provides the necessary intensive interventions and support that can start the recovery journey. Rehabilitation and recovery can both be understood as vehicles to obtain that which has been lost and both have come to mean more than an alleviation of symptoms and restoration of capacity. They 
incorporate the restoration of freedom, autonomy and inclusion. They have taken on a social meaning and service users' expectations of treatment have grown to include the restoration of self-worth and a meaningful life. Social recovery often takes many more years than symptomatic recovery, but it can lead to a greater sense of self-worth and achievement than was the case before becoming unwell, not so much a restoration but a renaissance.

\section{D for detention}

Detention is a last resort. The majority of my fellow service users agree that there is justification for detention, especially where there is a risk of harm to the self or harm towards others. However, assessment and detention under the Mental Health Act is a traumatic experience and must be carried out in a sympathetic and respectful manner. Reassurance and explanations really do help to defuse feelings of fear and humiliation and preserve the service user's dignity. Detention can create a barrier to the acceptance of treatment and to developing a therapeutic relationship with mental health professionals. The service user will focus more on the loss of freedom and choice and struggle to have these reinstated. Detention can negate all I have spelled out so far: freedom, autonomy, inclusion, rehabilitation and recovery. I myself have been detained under the Mental Health Act on two occasions and I recall my sense of downfall and panic - it was far from my understanding that detention was the beginning to recovery. I am fortunate that I am still in the care of the psychiatrist who sectioned me the last time 10 years ago and we have since built up a very trusting and therapeutic relationship. Although I did not look for an apology from him, he has assured me that my detention was a necessary stage in my journey to full recovery. I have learnt from him something of what it is like for those who detain - and my understanding is that this does create a dilemma for mental health professionals and that it is not an easy choice. I feel satisfied that in the majority of cases, detention will indeed be the last resort.

\section{E for equality}

Service users want to be considered as equal members of society, equal to people with and without mental health problems. First, they would like equality of process whereby everybody is treated in the same manner. Second, they would like equality of access to society's resources, not only wealth, food, housing and consumer goods, but also work, education and social capital. Obviously this has to be understood within the context of the inequalities in income and social division that capitalism allows, but individuals should not be unduly disadvantaged simply by the fact that they use mental health services or have mental health problems. Third, they should have equality of opportunity where the individual is able to do and be what he or she chooses and have access to the means of living life to the maximum of their capabilities. These are the equalities that the service user asks for and mental health professionals have a considerable role in ensuring that they are achievable.

\section{A for alternatives}

Treatment in the community is now a realistic alternative to incarceration in asylums. Perhaps there should now be alternatives to standard community treatment which would offer more intensive support but which would be less restrictive than admission to the psychiatric ward and also less restrictive in their remit than many crisis resolution and assertive outreach services. It is encouraging that some mental health trusts have invested in alternatives to admission such as crisis houses, especially since the home can feel a very unsafe place for someone experiencing serious psychosis. Hopefully, the future holds further alternatives: not only developments in alternative medications with fewer side-effects but also alternatives to medication, psychological and other therapies which are by no means helpful for everyone. Above all, I hope that there is eventually a cure for psychosis rather than just treatment.

\section{L for learning}

The service user may be dependent on services for a period of time to learn to lead a life of freedom, autonomy and inclusion. Ideally, the learning experience is a two-way process whereby mental health professionals enhance their expertise to help the mentally ill person through their experience of each individual's condition and circumstances. Both service users and mental health professionals should be working in a partnership of reciprocal learning curves. I also hope we can find a way to help society learn about mental illness and to educate the media so that its influence improves public perceptions of those affected by mental illness, leading to an erosion of discrimination and stigma.

\section{Fair Deal for all}

Although in some cases the relationship between service user and mental health professional can be in danger of becoming an unconstructive power struggle, it can be a truly fair deal for all where there is a spirit of communication, understanding, learning, concord and above all partnership between service users and professionals.

\section{Acknowledgements}

A draft of this paper was presented at the Royal College of Psychiatrists' 2009 Annual Conference in Liverpool. I thank Dr Helen Killaspy for reading the manuscript and giving useful feedback.

More information about the Fair Deal for Mental Health can be found on the campaign website: www.rcpsych.ac.uk/campaigns/fairdeal.aspx

\section{About the author}

Maurice Arbuthnott is Service User Representative at the Faculty of Rehabilitation and Social Psychiatry of the Royal College of Psychiatrists. 